Tropical Journal of Pharmaceutical Research December 2011; 10 (6): 833-840

(C) Pharmacotherapy Group,

Faculty of Pharmacy, University of Benin

Benin City, 300001 Nigeria.

All rights reserved.

Available online at http://www.tjpr.org

Research Article

http://dx.doi.org/10.4314/tjpr.v10i6.18

\title{
Perceptions of Disease State Management Among Pakistani Hypertensive Patients: Findings from a Focus Group Discussion
}

\author{
F Saleem ${ }^{1}$, MA Hassali ${ }^{1 *}$, AA Shafie ${ }^{1}$, S Bashir ${ }^{2}$ and M Atif ${ }^{3}$ \\ ${ }^{1}$ Discipline of Social and Administrative Pharmacy, School of Pharmaceutical Sciences, Universiti Sains Malaysia, \\ 11800 Minden, Penang, Malaysia, ${ }^{2}$ Faculty of Pharmacy, University of Sargodha, Punjab, Pakistan, ${ }^{3}$ Discipline of \\ Clinical Pharmacy, School of Pharmaceutical Sciences, Universiti Sains Malaysia, 11800 Minden, Penang, Malaysia
}

\begin{abstract}
Purpose: To explore the perceptions of disease state management among Pakistani hypertensive patients.

Methods: A focus group discussion was conducted with 19 hypertensive patients in order to obtain an insight into their self-management practices. The study was conducted in Sandeman Provincial Hospital, Quetta, Pakistan.

Results: Analysis of the focus group discussion yielded four major themes: (1) effect of hypertension on patients' physical, mental and social states; (2) involvement in self-management; (3) factors contributing to self-management; and (4) perception of patients towards antihypertensive agents. A majority of the patients admitted that they were involved in self-management of hypertension but their management strategies were influenced by social sources - peer or family - with very little information received from health care professionals. Exercise of self-management was strongly linked to the philosophy of the patients regarding nature of drug, as well as comparative advantages and disadvantages. Patients also expressed reservations about continuous drug usage for the management of chronic illnesses.

Conclusion: Patients suffering from chronic diseases such as hypertension tend to make individual and personal decisions about managing their illnesses. Patients seem to be more influenced by peers, family members and people with the disease condition, and thus try to manage their condition based on advice received from them. In addition, their philosophy of medication use and hypertension (being a chronic disease) prompts them to focus more on self-management practices.
\end{abstract}

Keywords: Self-management, Focus group, Hypertension, Perception

*Corresponding author: Email: azmihassali@usm.my; Tel: +604-6534085; Fax: +604-6570017 


\section{INTRODUCTION}

Hypertension is a major global concern. It has massive disturbing impact on the population, resulting in avoidable morbidities and mortalities. Hypertension alone is held accountable for more than $5.8 \%$ of deaths worldwide, loss of $11.9 \%$ years of life, adjusted life of $1.4 \%$ and decreasing life expectancy $[1,2]$. The disease leads to cardiac abnormalities such as myocardial infarction, stroke, heart failure, kidney failure and a number of other countless effects on the human body [3].

Standard treatment and management of hypertension normally follows, after clinical diagnosis, with pharmacotherapy and/or other non-pharmacological intervention such as lifestyle modifications [4]. On the other hand, some patients try to manage their condition on their own, independent of their physicians. Glasgow et al reported that no matter what health professionals do or say, patients are in control of these important selfmanagement decisions [5]. Self-management of disease is influenced by many factors [6]. Therefore, engaging patients in decisionmaking process by health care providers is very important in order to achieve the desired treatment outcomes. Furthermore, patients' beliefs about their disease status need indepth understanding by healthcare providers so that concordance with the treatment prescribed would be achieved. Selfmanagement occupies an important place in pharmaceutical care plan and needs to be addressed and understood properly by healthcare providers.

A simple statement defining selfmanagement was proposed by Creer et al as follows: "when the individual participates in treatment, he is engaged in selfmanagement" [7]. Barlow et al defined selfmanagement being the ability to manage the symptoms, treatment, physical and psychosocial consequences and life style changes inherent in living with a chronic condition [8].
One common belief regarding selfmanagement is its value and place in the overall treatment plans. It is important to mention that self-management is not an alternative to medical therapy but rather to provide a synergetic response along with the treatment. Normally patients take selfmanagement practices as priority and thus give less attention to adherence to their treatment regimen.

Within this context, some studies in developed countries have focused on patients' attitudes and behavior towards selfmanagement $[9,10]$. It has been reported that many patients struggle with self-management and therefore suffer from inadequate disease control and reduced quality of life [11]. There is paucity of data regarding this subject from developing countries, including Pakistan. This lack of information is even worse for remote areas of Pakistan which are disadvantaged with regard to formal education and access to health care facilities.

Hence, the objective of this study was to explore the perceptions of Pakistani hypertensive patients toward disease state management.

\section{METHODS}

\section{Study design}

Qualitative research approach was used for this study. This approach, based on focus group study, was adopted because it allows a flexible and in-depth exploration of patients' attitudes and experiences [12-14]. The methodology explores a wide extent of ideas and feelings that individuals have about certain issues, as well as reveals differences in perspective between groups of individuals $[15,16]$. It also examines how knowledge and ideas both develop and operate within a cultural context [17]. Most importantly, focus groups fill the gaps that are often exposed by Knowledge, Attitude and Practice (KAP) surveys and are therefore ideal for inductive 
approaches aimed at generating concepts and hypothesis which have far more potential for health education research than any other models [18]. Furthermore, this design is capable of assessing the needs of patients and can develop new services or redefine them [19]. They have a high level of face validity because elements of the discussion can be immediately confirmed or disputed among the patients [20].

\section{Ethical approval}

As there was no human ethical committee for non-clinical observational studies in the institution where the research was undertaken, permission for conducting the interviews was obtained from the medical superintendent of the hospital. In addition, written consent was obtained from each of the respondents.

\section{Study patients}

The study was conducted in Sandeman Provincial Hospital at the city of Quetta, located in northwest of Balochistan Province of Pakistan between June and August 2009. A total of 23 patients with clinically diagnosed hypertension and without any other concomitant diseases were approached purposely to participate in the study. A total of 19 patients agreed to participate and attended the focus group discussion sessions. Patients were divided into three groups with 6 patients each in two groups and 7 patients in the third group. The demographic characteristics of the patients are summarized in Table 1.

Table 1: Demographic characteristics of focus group (FG) patients

\begin{tabular}{|c|c|c|c|}
\hline Description & $\mathrm{FG} 1$ & FG 2 & FG 3 \\
\hline Subjects $(\mathrm{n})$ & 6 & 6 & 7 \\
\hline Age (mean \pm standard deviation) & $33.8 \pm 2.7$ & $31.7 \pm 3.4$ & $35.7 \pm 4.4$ \\
\hline \multicolumn{4}{|l|}{ Gender } \\
\hline Male & 6 & 0 & 7 \\
\hline Female & 0 & 6 & 0 \\
\hline \multicolumn{4}{|l|}{ Education } \\
\hline Primary & 0 & 0 & 0 \\
\hline Secondary & 0 & 1 & 2 \\
\hline Intermediate & 3 & 1 & 2 \\
\hline Bachelors degree & 3 & 3 & 2 \\
\hline Masters degree & 0 & 1 & 1 \\
\hline \multicolumn{4}{|l|}{ Locality } \\
\hline Urban & 5 & 4 & 5 \\
\hline Rural & 1 & 2 & 2 \\
\hline \multicolumn{4}{|l|}{ Income } \\
\hline Less than Pk Rs 10000 & 0 & 1 & 2 \\
\hline Pk Rs 10000-20000 & 3 & 4 & 3 \\
\hline Pk Rs 20000 and above & 3 & 1 & 2 \\
\hline \multicolumn{4}{|l|}{ Number of medications used } \\
\hline 2 & 6 & 4 & 5 \\
\hline$\geq 3$ & 0 & 2 & 2 \\
\hline \multicolumn{4}{|l|}{ Duration of disease } \\
\hline$<1$ year & 0 & 1 & 0 \\
\hline $1-3$ years & 5 & 3 & 2 \\
\hline $3-5$ years & 1 & 2 & 4 \\
\hline$>5$ years & 0 & 0 & 1 \\
\hline
\end{tabular}


Table 2: Schedule of topics for focus group study

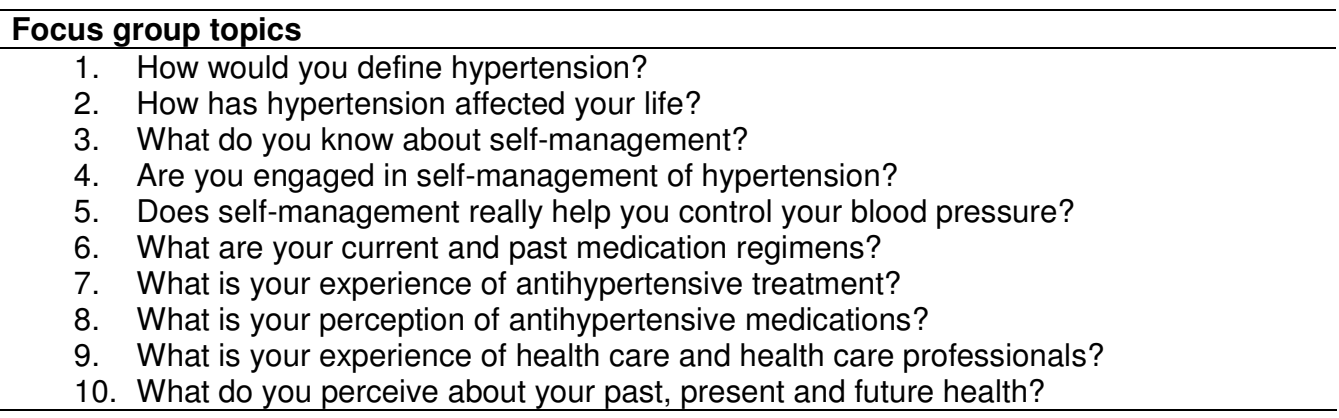

\section{Data collection}

Prior to the focus group discussions, a structured schedule of topics to be discussed was established. The topics were reviewed by a group of cardiologists working at the cardiology department for the purpose of validation. The topics, with little amendments, were then sent to an independent experienced moderator for further cleaning. The moderator ensured that topics to be discussed were at the level that patients would comprehend. The finalized schedule was again reviewed by the research team. All focus group discussions were audio-taped. Table 2 shows the topics that were finalized and discussed in the focus group.

\section{Data analysis}

Patients' responses were analyzed using standard qualitative research techniques [21]. Following transcription of all the interviews by the first author, major themes and subthemes were identified through coding of the quotes. At the point of data saturation, when no new concepts emerged, the themes were selected. Finally, all the research team members verified the coding undertaken for developing the major themes and subthemes through a consensus agreement.

\section{RESULTS}

The four major themes that were generated are as follows: (1) effect of hypertension on patients' physical, mental and social states;
(2) involvement in self management; (3) factors contributing to self-management; and (4) patients' perception of antihypertensive agents.

\section{Theme 1: Effect of hypertension on patients' physical, mental and social states}

Reduction in ability to carry our daily activities and mental stress were reported by almost every participant of the focus group. Patients expressed certain fears regarding impact of hypertension on their life as illustrated by the following quotes:

"I was in severe stress when I know that I suffer from hypertension. Now I will develop further heart problems and this will continue till my death" (P3, FG1).

"I know that I cannot perform moderate workouts now, this will result in further problems. My routine life is destroyed and I have to give up all what I use to do before" (P4, FG3).

Socially, patients' family members and financial status were badly affected by hypertension. Some patients have to leave their current jobs as they were unable to perform strenuous jobs, while others mentioned the impact of treatment on their monthly expenditure.

"I use to work with heavy machines, now I feel tired and fatigued. I cannot find a desk 
job too so my output at work is getting decreased and so is my progress" (P2, FG2).

"The medicines are too costly and because of my problem my family is also restricted to specific diet. With my income it is not possible to cover all expenditures. My disease has made my life problematic" (P3, FG3).

\section{Theme 2: Involvement in self-management}

A majority of patients admitted that they were engaged in self-management. They declared other hypertensive patients, peers and family members as the sources of information for self-management. Some stated that health care professionals were responsible for this practice.

"I read that salts, oily food and smoking can increase blood pressure. If I can adopt regular exercise and stick to medication, I will have no problems. I am doing that and I feel I am ok" (P1, FG1)

"I started using garlic in my food. I am also having green tea thrice a day. I was told by my friend that I can control my blood pressure like this and it is working" (P2, FG1)

Some patients added that after diagnosis of hypertension, they tried to know more about it. It was an approach which was independent of them.

"My self-management started the day I knew I had hypertension. I go through books, digests, internet, discussed with friends that what are the causes, effects and problems related with hypertension" (P5, FG1)

"Now I do not use fatty products, no outside food and try to use lots of fruits and liquids. I even bought a BP apparatus so I can check my blood pressure daily" (P1, FG3)

"I came to know that brisk walking is best for controlling hypertension. For me selfmanagement is going for a walk every day and keeping away from stress and tension" (P1, FG3)

\section{Theme 3: Factors contributing to self- management}

Nearly all the patients indicated that heavy expenses in the form of physician fee, medications and diagnostic tests as the major reason for self management. An interesting claim was that hypertension is untreatable; patients expressed no use in consulting physicians regularly until or unless there is a severe problem faced by them.

"What is the use of going to physician when your condition is not treatable? It is wise to carry out management at home and that always works" (P1, FG1)

"I know that if I go to the doctor, he will charge me a huge fee and will give me the same old medicines. May be he will add one more. So I prefer to stay at home and try to control my blood pressure myself' (P3, FG2)

Whenever I go out with family, I feel relaxed and my blood pressure remains in controlled range. Even for days I do not take medicines and nothing happens. I think that it is the routine (activities) that controls my blood pressure and not the medications so I manage my routine work and have no problem. (P4, FG1)

\section{Theme 4: Perception of patients towards antihypertensive agents}

General perception of patients about their medication seemed quite unique. Knowledge related to hypertension and its management was on the average level but still some patients had reservations about its treatment and management.

"Drugs are hot (warm) in nature. They enter the stomach and increase temperature which interferes with digestion. At the same time, body temperature rises too. That is why when 
I feel good, I do not take medicines and try to control it by diet" (P6, FG2)

"My father had hypertension for 15 years. He was on strict diet plan and used his medication regularly. Even then, his blood pressure was not controlled; so as I see, diet plans, walk, medication etc has no effect on hypertension. Once it develops, it is forever and you cannot do anything" (P4, FG1).

"I use medicines properly but when I feel sad, or I am doing some important work my blood pressure rises again. My doctor told me that if I use drugs properly I won't feel this. It means that this condition is not treatable and whatever I do, it will keep coming back. So why should I spend my money on expensive drugs?" (P5, FG3)

There were also reservations regarding alternative medicine use in patients with hypertension. Some patients emphasized that the use of traditional remedies gives much better results.

"I saw my parents treating me and other kids with herbs, home remedies, amulets, etc. They said that natural products do not interfere with human body. I was brought up with the use of these things. Even for hypertension, I try traditional products and only visit the doctor when I feel seriously ill" (P6, FG2).

"I do use medicines prescribed by my physician but at the same time I use some traditional remedies as my blood pressure was not controlled with drugs alone; but when I started traditional remedies along with the drugs, I faced no problem. It is a good combination and I even discussed this with my physician" (P2, FG3)

\section{DISCUSSION}

The present study highlights the perception of hypertensive patients regarding selfmanagement and medication use for the management of hypertension in Pakistan which was not previously reported in the literature. The study shows that patients with hypertension have their lives adversely affected by this long-term condition. Patients suffering from chronic conditions tend to make routine decisions about their illnesses and the way to manage them. This may include medication, prophylactic measures and self-management measures. Interestingly, self-management strategies that are employed by patients are their own decisions and often results in worsening of symptoms [22].

In the present study, patients tended to focus on self-management and at the same time considered self-management superior to orthodox treatment. The use of antihypertensive agents only when symptoms are aggravated clearly indicates that patients feel self-management to be more important than pharmacotherapy. This clearly reflects the level of interaction with their physicians. Moreover, limited counseling services are available to the patient and this adversely affects the ability to make informed decisions. Consequently, patients place more value for information received from peers, family members, and people with past similar experience and thus try to manage their condition based on the advice received. While it may not be appropriate to state that all the advice are wrong, there is no doubt that such advice does not emanate from professionals and may vary from patient to patient. Therefore, self-management strategies that are employed by patients often result in further complications.

For proper implementation of selfmanagement in therapeutic plans, amalgamation of behavioral strategies to improve self-management requires a multidisciplinary team effort (physician, pharmacist and nurse). Teaching self management is time-consuming, requiring repeated contacts with health care professionals for education, self-monitoring and assessment of progress. The approach to patients should be individualized, taking 
into consideration their culture, economic situation, knowledge and beliefs regarding the disease and treatment, response to medication and changes in status over time [23].

Lack of human recourses in health sector is considered a major hurdle in the delivery of optimal health care to all [24]. Pakistan is not an exception in this regard as she faces a severe shortage in both the number of professionals and health care facilities. In 2008, only 8 physicians, 1 dentist and 6 nurses/midwifery were available to a population of 10,000 [25]. This results in the development of medical pluralism, whereby the patient uses different systems for healing. In the current study, it was obvious that patients focus more on complementary and alternative medicine (CAM) than on orthodox therapy. Patients made independent but similar assessments regarding the use of modern medicines. It was also observed that orthodox treatment is not as popular with the population under study as it is in the western world [26, 27]. Perceived benefits of, and barriers to, treatment regimen play a vital role in achieving therapeutic success [28]. However, patients in our study seem unsatisfied with medication prescribed to them. There seems to be a general belief among the populace that orthodox medicines are more harmful than beneficial. This may be another reason why there is more emphasis on self-management strategies among the study participants.

\section{Limitations of the study}

This study has limitations that are inherent to other qualitative studies. Qualitative studies are often limited in generalization. The study was based on a limited sample of qualitative focus group discussion with hypertensive patients at one institute in a city, but saturation of ideas was reached. Our finding may not, therefore, be generalized to the hypertensive population in Quetta, Pakistan as a whole, and therefore, requires reinforcement through further work.

\section{CONCLUSION}

The present study has provided an insight into an aspect of the experience of patients with hypertension in Quetta, Pakistan. The findings indicate that patients employ self management strategies but these strategies are mostly based on their experiences but with minimal professional input. This study provides the key ingredient that needs to be included in a disease-specific selfmanagement program. The importance of medications and self-management should be clarified to the patient prior to initiation of therapy so the patients can benefit maximally from the two measures. Together with antihypertensive medications and professional input regarding self-management by professionals, these programs can help in achieving a controlled status of the disease which is one of the biggest hurdles in hypertension treatment and management.

\section{REFERENCES}

1. Kannel WB. Blood pressure as a cardiovascular risk factor. JAMA. 1996; 275(20): 1571-1576.

2. Chobanian AV, Bakris GL, Black HR, et al. Seventh report of the Joint National Committee on Prevention, Detection, Evaluation, and Treatment of High Blood Pressure. Hypertension. 2003; 42(6): 1206-1252.

3. Pierdomenico SD, Di Nicola M. Esposito AL, et al. Prognostic Value of Different Indices of Blood Pressure Variability in Hypertensive Patients. Am J Hypertens. 2009; 22(8): 842-847.

4. JNC. The Seventh Report of the Joint National Committee on Prevention, Detection, Evaluation, and Treatment of High Blood Pressure (JNC 7), 2003 (updated December 2003) [cited July 1, 2011 ]; Available from http://www.nhlbi.nih.gov/guidelines/hypertensio n/jnc7full.htm

5. Glasgow RE, Anderson RM. In diabetes care, moving from compliance to adherence is not enough. Diabetes Care. 1999; 22(12): 20902092.

6. Clark NM. Management of chronic disease by patients. Annu Rev Public Health. 2003; 24: 289-313.

7. Creer T, Renne C, Christian W. Behavioral contributions to rehabilitation and childhood asthma. Rehabil Lit. 1976; 37: 226-232.

8. Barlow J, Wright $C$, Sheasby J, Turner $A$, Hainsworth J. Self-management approaches for people with chronic conditions: $A$ review. Patient Educ Couns. 2002; 48: 177-187. 
9. Lavery K, O’Neill B, Elborn JS, Reilly J, Bradley JM. Self-management in bronchiectasis: the patients' perspective. Eur Respir J. 2007; 29: 541-547.

10. Bodenheimer T, Lorig K, Holman H, Grumbach K. Patient Self-management of Chronic Disease in Primary Care. JAMA. 2002; 288(19): 24692475.

11. Bosworth HB, Powers BJ, Oddone EZ. Patient SelfManagement Support: Novel Strategies in Hypertension and Heart Disease. Cardiol Clin. 2010; 28: 655-663.

12. Quine S. Interviews. In: Kerr C, Taylor R, Heard G, eds. Handbook of Public Health Methods. Sydney, Australia:: McGraw-Hills, editor; 1998.

13. Smith F. Qualitative interviews . Research methods in pharmacy practice. London: Pharmaceutical Press; 2002.

14. Berg B. Qualitative Research Methods for the Social Sciences. 5 ed. Boston, MA: Allyn and Bacon; 2004.

15. Rabiee F. Focus-group interview and data analysis. Proceedings of the Nutrition Society. 2004; 63; 655-660.

16. Kitzinger J. Qualitative Research: Introducing focus groups BMJ. 1995; 311; 299-302.

17. Kitzinger J. The methodology of focus groups: the importance of interactions between research participants. Sociol Health III. 1994; 16(1): 103-121.

18. Mullen PD, Reynolds $R$. The potential of grounded theory for health education research: linking theory and practice. Health Educ Monographs. 1978; 6; 280-294.

19. Burrows $D$, Kendall S. Focus groups: what are they and how can they be used in nursing and health care research? Social Sciences in Health. 1997; 3: 244-253.
20. Lavery K, Neil OB, Elborn JS, Reilly J, Bradley JM. Self-management in bronchiectasis: the patients' perspective. Eur Respir J. 2007; 29; 541-547.

21. Berkwits $M$, Inui TS. Making use of qualitative research. J Gen Intern Med. 1998; 13: 195199.

22. Azar H, Inger E. Symptom recognition and health care seeking among immigrants and native Swedish patients with heart failure. BMC Nursing. 2008; 7(9).

23. Gerrish K. Individualized care: its conceptualization and practice within a multiethnic society. $J A d v$ Nurs. 2000; 32(1): 91-99.

24. Islam A, Zaffar Tahir $M$. Health sector reform in South Asia: new challenges and constraints. Health Policy. 2002; 60(2): 151-169.

25. Aslam SM. Shortage of doctors, indifference seriously undermining public health care system in Pakistan. 2010 [updated July 20, 2010; cited July 1, 2011]; Available from: http://www.allvoices.com/contributed-news/63 52628-shortage-of-doctors-indifference-seriou sly-undermining-public-health-care-system-inpakistan.

26. Edwards SD. Traditional and modern medicine in South Africa: a research study. Soc Sci Med. 1986; 22; 1273-1276.

27. Bichmann W. Primary health care and traditional medicine considering the background of changing health care concepts in Africa. Soc Sci Med. 1979; 13B: 174-182.

28. Cerkoney KA, Hart $L K$. The relationship between the health belief model and compliance of persons with diabetes mellitus. Diabetes Care. 1980; 3(5): 594-598. 